\title{
The telescope in the making, the Galileo first telescopic observations
}

\author{
Alberto Righini \\ Dipartimento di Fisica ed Astronomia dell'Università degli Studi di Firenze \\ Largo E. Fermi 2 \\ 50125 Firenze, Italy \\ email: alberto.righini@unifi.it
}

\begin{abstract}
In the first part of this paper we briefly discuss some historical constraints useful for understanding when Galileo for the first time aimed his telescope to the Moon which most probably was the first astronomical object observed by the Scientist. In the second part we discuss the dates of the observations on which the etchings, published in the Sidereus Nuncius, are based. It results that the five etchings refer to observations performed in December 1609 and January 1610. The measurement of the position, of some peculiar structures of the lunar surface clearly represented by Galileo in the etchings, shows that he was very careful in trying to produce a faithful graphical rendering of what he was observing.
\end{abstract}

Keywords. History and Philosophy of Astronomy, Galileo Galilei, telescope.

\section{Introduction}

The year 2009 was devoted to astronomy, to celebrate two great events occurred in 1609, four hundred years ago. In that year, in Prague, the astrologer (and astronomer) Johannes Kepler published his Astronomia Nova in which he enunciated the first two of the three laws, on planetary motions which we, today, designate as Kepler's Laws; in Padua, a Professor of Mathematics (but he was also teaching Astronomy and Cosmography) Pisan in birth but Florentine by adoption, built a powerful tool for naval warfare and for observing the universe by transforming an optical toy, used by ladies and gentlemen for spying their secret loves in the Italian gardens. Professor Galilei son of the late Vincentio Galilei, nobleman in Florence (this was the name of that ingenious lecturer who desperately wanted to return to Florence) was a well known Professor in Padua, very skilled to occupy all available areas of academic power, and a good friend of influent personalities in Venice; he was also well introduced in many cultural circles of Europe. The intelligent use of his new optical instrument, which he defined as cannon or optical cannon, brought several advantages to Galileo: he obtained tenure for life at the University with a salary of 1000 florins per year, and the Venetian Senate asked him to build twelve telescopes for the Navy. Galileo was not only a great academic, very well acquainted with the University tribal uses, but also a skilled and careful researcher of things of nature, in the language of the time he was a natural philosopher. In this context we should consider the Galileo's almost spontaneous deed of aiming his precious tube to the sky: this was a deed of a physicist not of an astronomer, a deed of someone curious about the physical nature of the celestial objects; the Moon was most probably the first object to be observed, and therefore we may ask ourselves, once again, when this happened (A. Righini 2009). 


\section{About the date of the first Galilean observation of the Moon}

Galileo himself tells us the story of his re-discovery of the telescope in a letter to his brother in law Benedetto Landucci dated August 29, 1609. In this letter Galileo states that in Venice news arrived that a Fleming had presented to the Count Maurice lof Nassau] a glass by means of which distant objects could be seen distinctly. Upon hearing these news I returned in Padua and set myself to thinking about the problem. The first night after my return I solved it, and on the following day I constructed the instrument and sent word to some friend in Venice with whom I had discussed the matter the day before.... (Favaro 1968); the telescope, that Galileo had perfected had 8-10 enlargements. We can therefore consider that in Venice the news of the Dutch spyglass goes back to the end of June or early July 1609, in fact, in that period Augusto Bartoli, Tuscan ambassador in Venice, writes to Belisario Vinta, State Secretary of the Grand Duke in Florence, that there was around in the Serenissima Republica (Venice) a person willing to sell the secret of a device to see far.

Galileo employs one or two months to improve the telescope and on August 25th, he submits the telescope, as an invention by his own, to the Doge Leonardo Donato. On August 29th; from Florence, Enea Piccolomini Aragona writes to Galileo on behalf of the young Grand Duke of Tuscany Cosimo II asking a telescope, or the recipe for building one in Florence. We have also another letter which reaches Galileo from his friend Don Antonio de' Medici in Florence asking him a telescope, dated September 19. We are sure therefore that Galileo until September 19, 1609, after the improvements of the telescope did not return to Florence, as he was accustomed to do every year before the beginning of the academic year. In early November we find in the Galilean correspondence a letter in which our scientist writes to Belisario Vinta that he just returned to Padua. Everything seems to indicate that Galileo was in Florence after September 19, 1609 and he was back in Padua before October 30,1609.

Given as certain the presence in Florence in the Fall of 1609, which is confirmed also by other sources (Drake 1978), let us examine the letter written by Galileo to Belisario Vinta on January 30, 1610 in which he announces that the Sidereus Nuncius (Starry Messenger) was in press. Galileo describes to the Tuscan Secretary of State the surface of the Moon and claims that he had already shown our satellite to the young Cosimo II Gran Duke of Tuscany, although with an imperfect telescope. We may therefore infer that the first observations of the Moon made by Galileo may be dated before October 30, 1609. From the analysis of lunar phases of that period we understand that the first days of October are those in which perhaps the Grand Duke of Tuscany has observed the mountains and valleys on the Moon, albeit imperfectly, with a telescope with a ten enlargements. Of course it is not reasonable to think that Galileo, in the presence of the Grand Duke decided to turn the telescope to the sky without knowing what Cosimo II would have observed and it is therefore logical to consider that the first observations of the Moon by Galileo date back at least to previous lunation. With these arguments we can conjecture that the first observations of the Moon, by Galileo were performed in Padua in early September of 1609 but with a telescope delivering no more than 10 enlargements, we discard the lunation of August because at that time the telescope was still very imperfect and we do not find any hint on Galileo's correspondence of an astronomical use of the new instrument.

We should note that the men of the Gran Duke of Tuscany secret service, had already aimed to the sky the imperfect Dutch telescopes they had in their hands, reporting that using those spyglasses some nebulae were resolved in a multitudes of stars which were not visible with the naked eye. 


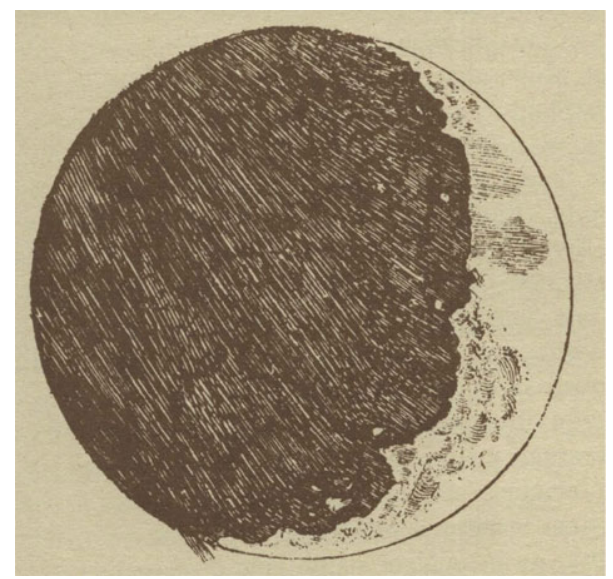

Figure 1. The first etching of the Moon in the Sidereus Nuncius (Starry Messenger). The moon shows an illuminated fraction of $(21 \pm 2) \%$.

\section{The Lunar etchings in the Sidereus Nuncius}

Discussing about the Galileo's first telescopic observations, we should discuss also about the epoch of the lunar observations which gave origin to the etchings of the lunar surface we find in Galileo's Sidereus Nuncius (Starry Messenger), the booklet published in March 1610, which announces to the entire world the new celestial discoveries. The idea to print the Nuncius, as we know it now, may be dated some days after January 7, 1610 when Galileo realized that those stars, that he (or some of his friends) had observed around Jupiter, were four Jovian moons. However Galileo probably had already in December 1609 the idea to print his observations of the Moon carried out in November and December 1609.

Proof that Galileo had already collected a considerable experience in observing the Moon is given by the letter he writes just on January 7, 1610 to Don Antonio de' Medici in Florence, in which he explains how difficult is to work with the telescope. In this letter Galileo examines various aspects of the lunar surface by enriching the words with many approximate drawings. It should be noted that we do not have the original letter but a copy of it and possibly the letter may be one he had never sent. In the letter closure, Galileo incidentally writes, that on that evening he noted Jupiter accompanied by three fixed stars, invisible with the naked eye for their smallness and aligned along the Ecliptic with the planet. In this letter to Don Antonio, Galileo claims to have a telescope of 20 enlargements and not 30 as he later states in the Nuncius.

A dating of the Nuncius etchings must take account of what was written by Guglielmo Righini (GR)(G. Righini 1978), who studied in depth the problem, with whom we disagree in part. The procedure adopted by GR is based on the measurement of the illuminated fraction of the Moon and on the position of the center of the drawing to compute the libration. This method implicitly admits that Galileo, graphically transposing telescopic observations, was able to maintain the relative positions of the observed structures. As known in the Galilean (or Dutch) telescope it is not possible to overlap a reference grid on the image due to optical structure of the instrument, however we know that on the occasion of observation of Jupiter satellites, Galileo was able to solve this problem watching with the eye, which was not applied to the telescope, a distant sheet of paper on which he draw a set of concentric circles or an orthogonal grid. The brain of the observer merges the two images by providing a reference scale, it may be that this device 
was used by Galileo also to draw the Moon. We should also consider that the field of Galileo's telescope was smaller than the Moon angular size.

The first etching of the Nuncius (Figure 1) refers to a phase between New Moon and First Quarter. In this image, simply tracing the chords perpendicular to line joining the cusps and evaluating the ratio of the chord lengths which lie in the bright and those in the dark part of the Moon we may evaluate the illuminated fraction which results to be $(21 \pm 2) \%$. Of course, the terminator, which correctly Galileo draws as irregular, must be interpolated. Using the data available on the web thanks to JPL project Horizon (Horizon 2009) it is possible to compute the illuminated fraction of the Moon observed in Padua from July 1609 to February 1610. Three dates of the year 1609 are compatible with the result about the illuminated fraction of the Moon and with the historical constraints: October 2, November 1, December, 1. To make a choice we superimposed on the image the appropriate Stonyhurst disk to calculate the selenographic latitude of the center of the lunar apparent disc with the JPL Horizon program, properly rotated so that the coordinates of the center of the Mare Crisium, clearly indicated by Galileo, fit at best. Than we selected four areas: Plana, Capella, Rabbi Levi and Baco changing the epoch of the observation trying to obtain the best fit. This procedure has led us to discard the dates of November 1,1609 and October 2,1609, and converging on December 1, 1609 with a mean absolute error of $2.5 \%$ in unit of lunar diameter in the positioning which should be compared with the value of $4.6 \%$ for the November date and again $2.5 \%$ for the October date. The December date is the more plausible for the following considerations: a) on October 2, Galileo was in Florence and did not have a proper telescope, b) the illuminated fraction on December 1st is more in agreement with the drawing, c) Galileo that day would have had more time to work, d) Galileo must have spent the whole month of November to improve the telescope, while producing the instruments commissioned by the Serenissima and only at the end of the month he had in his hand an appropriate instrument delivering 20 enlargements. We want once again to pay a tribute to Galileo physical and experimenter skill: the small error we found in assessing the coincidence of the lunar structures means that Galileo's drawings have clearly the meaning of measurements, and not only, as suggested by O. Gingerich Gingerich 2009, an attempt simply to give the idea of the mountains and plains observed on the Moon with his instrument.

The following two etchings (Figure 2, drawings 2 and 3) are dated by GR relying mostly on libration, the first of the two, which refers to the Moon in the first quarter is attributed to December 3, 1609 and the third, which represents the Moon at last quarter, to December 18,1609 with a libration in latitude -5.9. On these dating we do not object. GR dates the fourth drawing (Figure 2, drawing 4), representing a Gibbous Moon at an age between the Full Moon and the Last Quarter, a few days before December 18 (we would say the 17). It should remarked that in this case the etching in the Nuncius is not in chronological order with the previous one (Figure 2, drawing 3); but we could make the hypothesis, considering its position in the book, that this etching might refer to the day January 16, 1610, for that the astronomy is the same which supports the dating to December 17. The fifth etching is identical with the third one, it is again the Last Quarter and technically seems that the printer uses the same plate which printed the third image. GR suggests that this image is an editing error. Maybe! However we may consider that Galileo has really observed the Moon at the last quarter on January 18, 1610 (in this date the astronomical circumstances were similar to those of the December 1609 Last Quarter), and, perhaps, to speed up the publication of the booklet (and to save money) he deliberately duplicated the third etching. 

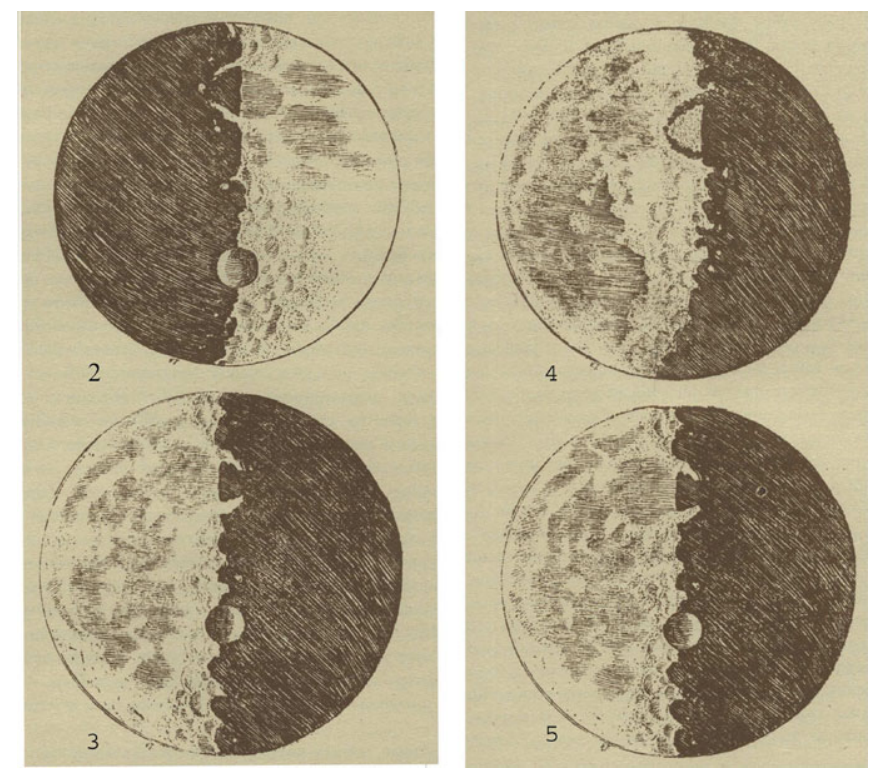

Figure 2. The other four etchings of the Moon in the Sidereus Nuncius. The dates of the observations of the etchings 2 and 3 are respectively: December 3 and December 18, 1609. It may be guessed etching 4 refers to an observation made on December 17, 1609 or on January 16, 1610. The etching 5 might be an editorial error because identical to 3 (or might also be inserted by Galileo to represent an observation performed on January 17, 1610 since the Moon in that night was very similar to that of the December 18, 1609).

Let us compare our results with those exposed in two recent papers one signed by E. Whitaker (Withaker 2009), which appeared in the catalog of the exhibition on Galileo held at Palazzo Strozzi in Florence to celebrate 400 years from the first telescopic observations, and the other signed by O. Gingerich (Gingerich 2009) on the puzzling copy of the Sidereus Nuncius owned by the Martayan and Lan Company in New York. Withaker proceeds to an accurate dating of the lunar drawings existing in the National Library in Florence and dates the etching in the hypothesis that those drawings were the originals supplied by Galileo for making the etchings. The first lunar etching in the Nuncius (Figure 1) is dated by Witaker November 30 and confirmed by Gingerich, we would prefer, for the considerations set above, December 1, the second and the fourth are dated December 3 and December 18 as already stated by Guglielmo Righini, dates on which we also agree. The third is assigned by Witaker to December 17 in agreement with our results, but Gingerich also suggests that it might refer to January 16, 1610. It is very interesting that among the Galilean materials, in the Florence National Library, Whitaker identifies an image which can surely dated to January 19, 1610 thanks to a nearby bright star recorded by Galileo, which might be the $\theta$ LIB occulted that night by the Moon, demonstrating that Galileo continued to observe the Moon at least in the two first decades of January 1610 while writing his Starry Messenger.

\section{Conclusions}

We are convinced (with many others) that Galileo, as soon as he had available a suitable instrument, aimed his 10 enlargements telescope to the sky and in particular to the Moon; this happened in early September of the year 1609. When he had available a more advanced telescope delivering 20 enlargements, thanks to experience gained in constructing telescopic ordered by the Doge, in November 1609, he undertook a systematic 
observation of the Moon, this project very likely began in the first of December of the year 1609 and probably ended on January 20, 1610 (as far as it concerned the Starry Messenger). Realizing his drawings Galileo used some artifices, to maintain in his drawings the proportions of the observed structures. And, as usual when we study in depth the work of Galileo, we are amazed by the quality of his work!

\section{References}

Righini, A. 2009, Sulle date delle prime osservazioni lunari, Giornale di Astronomia, 35, 3

Favaro, A. 1968, National Edition of the Le opere di Galileo Galilei, G. Barbera, Florence, Vol. X, p. 253

Drake, S. 1978, Galileo at work, The University of Chicago Press, Chicago

Righini, G. 1978, Contributo alla interpretazione scientifica dell'opera astronomica di Galileo, Supplemento agni annali dell'Istituto e Museo di Storia della Scienza, Firenze

JPL Program Horizon, http://ssd.jpl.nasa.gov/horizons

Gingerich, O. 2009, The curious case of the M-L Sidereus Nuncius, Galilaeana VI, 2009

Withaker, E. A. 2009, Identificazione e datazione delle osservazioni lunari di Galileo, in P. Galluzzi Galileo Immagini dell' Universo dall'antichità al telescopio Giunti, Firenze 